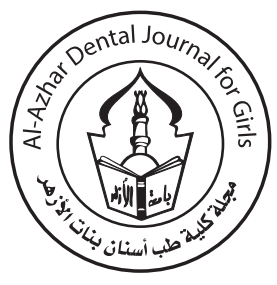

\title{
Evaluation of Coconut Oil Pulling vs. Whitening Mouthwash as Home Teeth Whitening Methods
}

\author{
Shahad H. Rajab ${ }^{1}$, Lujain K. Al-Hindii ${ }^{1}$, Sahar M. Elmarsafy ${ }^{2 *}$
}

Codex : 05/21.01
azhardentj@azhar.edu.eg
http://adjg.journals.ekb.eg

DOI: 10.21608/adjg.2020.32845.1269

Restorative Dentistry

(Removable Prosthodontics, Fixed

Prosthodontics, Endodontics, Dental Biomaterials, Operative Dentistry)

\section{KEYWORDS}

Coconut oil, Oil pulling, Tooth

whitening, Tooth sensitivity

\begin{abstract}
Purpose: This study was aimed to evaluate whitening efficacy, tooth sensitivity, and soft tissue irritation of coconut oil pulling as a home whitening method compared to an over-the-counter whitening mouthwash. Material and Methods: A randomized controlled clinical study was done on 60 females at Umm Al-Qura University, Faculty of Dentistry. The participants were divided into two main groups $(n=30)$, to test two whitening agents; Study Group "Coconut Oil Swish" and Control Group "Crest 3D White". Color measurement was done using the VITA Easyshade ${ }^{\circledR}$ Advance device at three times; the baseline, after one week and after two weeks of whitening. Pain assessment " tooth sensitivity \& soft tissue irritation" was done by utilizing the Pain Rating Scale "Wong-Baker FACES". Results: The results in this study revealed no significant difference between lightness of the both group but the color differences $(\Delta \mathrm{E} 1 \& \Delta \mathrm{E} 2)$ in the Crest $3 \mathrm{D}$ White (control group) were scientifically higher than in the Coconut Oil Swish (study group). Regarding the pain assessment, a significant difference in pain scores was found between the two groups as Coconut Oil Swich (study group) recorded lower pain score than Crest 3D White (control group). Conclusion: Although the Coconut oil pulling revealed a whitening efficacy after two weeks of use; the whitening mouthwash that contains $1.5 \%$ hydrogen peroxide recorded higher color change at one- or two-weeks use. Coconut oil pulling causes less tooth sensitivity and/or soft tissue irritation during regular use when compared to the whitening mouthwash that contains $1.5 \%$ hydrogen peroxide.
\end{abstract}

\section{INTRODUCTION}

Tooth surface discoloration considered to be the main reason to seek dental care as it can affect esthetic appearance of the patient's smile, it can also cause negative psychological effects to the patient. In order to

1. Internship Dentist, Faculty of Dentistry, Umm Al-Qura University, Kingdom of Saudi Arabia.

2. Assistant Professor of Operative Dentistry, Faculty of Dental Medicine for Girls, Al-Azhar University, Egypt and Faculty of Dentistry, Umm Al-Qura University, Kingdom of Saudi Arabia.

* Corresponding author email: s_elmarsafy@yahoo.com 
make the correct treatment plan, a dental clinician must understand the etiology of tooth discoloration which can be divided to two main categories either internal discoloration or external discoloration ${ }^{(1-4)}$.

According to Food and Drug Administration (FDA), there is a difference between the two terms tooth "bleaching" and tooth "whitening". Tooth "bleaching" is used to describe whitening process using active ingredient mainly peroxide that will whiten teeth beyond their natural color by releasing oxygen molecules which get inside the enamel micro-fractures breaking the stain pigmentation. While tooth "whitening" means, restore the natural color of the teeth by removing stain debris by either mouth rinses or toothpastes ${ }^{(5)}$.

There is a variety of chemical bleaching products that can be used at the clinic or at home with different bleaching agent concentrations. In home bleaching gel that usually done for several weeks, mainly two molecules are used; hydrogen peroxide which usually ranges from $3 \%$ to $10 \%$ or carbamide peroxide in concentrations ranging from $5 \%$ to $35 \%$; the latter being most common as a home bleaching material ${ }^{(6)}$. Other techniques that can be used at home include whitening strips, toothpastes and mouthwashes "over the counter products" ${ }^{(7,8)}$.

Nowadays there are numerous oral hygiene agents, and mouthwashes consider to be the most popular one; they control the cariogenic biofilms chemically and have remineralizing properties. Because of increasing the interest of patients' in recent years about dental aesthetics, the number of mouthwash products containing hydrogen peroxide (HP) has risen significantly ${ }^{(9)}$.

At-home and in-office tooth bleaching methods have many advantages and disadvantages. However, the self-applied whitening products which contain peroxide must be used carefully as they might cause oral/ gingival irritation and tooth hypersensitivity ${ }^{(7,10,11)}$.

On the other hand, many natural methods were used in order to whiten teeth at home without any clinical evidence as baking soda with lemon, ba- nana peel and oils as olive and coconut. Oil pulling is an ancient Indian remedy that has been used to prevent oral malodour, gingival bleeding, and dry mouth, it has also been thought to strengthen the teeth and prevent decay. Several natural oils have been used such as olive, sunflower, sesame, and coconut oils ${ }^{(12)}$.

Recently, the use of oil pulling has become more popular aiming to treat and prevent several oral and systemic problems such as migraine, hypertension and diabetes mellitus ${ }^{(13)}$. In the past couple of years, the use of oil pulling in oral health has increased due to its cost-effectivity and harmlessness; one of the common uses is home whitening. Some of the great advantages of this method is that it is extremely simple to use at home without the need to follow complex procedures and steps, and that natural oils are highly available and easy to obtain. Other advantages of natural oils over other commercially available products are that they do not cause staining and have a lower chance of causing an allergic reaction or an unpleasant taste.

Despite the many advantages of oil pulling, there are also a number of disadvantages; one of the major drawbacks of this method is that it requires a longer time for results to actually been seen, this requires compliance and maintenance for longer periods which could be undesirable by many patients. Other disadvantages could be that some patients may not appreciate the taste or consistency of natural oils and prefer other bleaching methods ${ }^{(13)}$.

The effectiveness of many tooth bleaching agents has been assessed either visually with shade guides or instrumentally with electronic color measuring devices. And although the in-vitro studies offer a good way to screen the potential bleaching efficacy, the randomized controlled trials are the gold standards ${ }^{(14)}$.

Therefore, the present study aimed to perform an in-vivo study to evaluate whitening efficacy, tooth sensitivity, and soft tissue irritation of coconut oil pulling as a home whitening method compared to an over-the-counter whitening mouthwash. 


\section{MATERIAL AND METHODS}

\section{Study design:}

A randomized controlled clinical study was carried out on female subjects at Umm Al-Qura University, Faculty of Dentistry to assess the efficacy and sensitivity of one type of coconut oil pulling as a home whitening method compared to an over-the-counter whitening mouthwash. Sample sizing was calculated and thus, the number of participants estimated to be 60. The examination and shade determination were carried at Umm Al-Qura outpatient dental clinics by the authors who were trained and calibrated.

Ethical approval and inform consent study approval was obtained from the Institutional Review Board-IRB \# 44-15 dated 28-12-2016 (research ethics committee) at Faculty of Dentistry, Umm Al-qura University. All the participants in the study were signed the informed consent form and they were informed that their personal data would be very confidential.

\section{Study population:}

The study subjects included in the study were dental interns, dental students and female staff members at Faculty of Dentistry, Umm Al-Qura University. Inclusion criteria were as followings: adult female patients aging 18 - 30-year-old; all upper and lower anterior teeth are existing and without signs of imperfections or caries or fillings or unvital; ready to stop using tobacco during whitening procedure; agree to sign the consenting form; com- mitment to the scheduled follow up ${ }^{(15,16)}$. While the exclusion criteria were as followings: presences of gross dental anomalies (malformation, fracture, amelogenesis imperfecta, fluorosis, tetracycline stain... etc.); whitening procedures either professional or individual in the past year; using medications that can change the tooth color; have had a known adverse reaction to peroxide; cold sensitive teeth or were pregnant or nursing; recently undergoing serious treatments such as orthodontic or orthopaedic or psychologic ${ }^{(15,16)}$

\section{Study grouping:}

After signing the informed consent, each participant was given a specific number, and then they all were randomly divided into two main groups $(\mathrm{n}=$ 30 ), according to the type of the whitening agent which were; commercially available coconut oil pulling (Study Group: Coconut Oil Swish, Lauren Naturals) and over-the-counter whitening mouthwash (Control Group: Crest 3D White, Procter \& Gamble) as shown in Table (1).

\section{Bleaching procedures:}

After assigning the participants into the two groups, each participant received one bottle of bleaching agent accordingly, which were used for two weeks. All the participants were given verbal and written instructions on the method and frequency of use following the manufacture directions and they were informed about the follow up sessions which were; the baseline (before whitening), after one week of whitening and after two weeks of whitening.

Table (1): Whitening agent types, manufacture, composition and directions of use

\begin{tabular}{|l|l|l|l|}
\hline Product Name & \multicolumn{1}{|c|}{ Manufacture } & \multicolumn{1}{c|}{ Composition } & \multicolumn{1}{c|}{ Manufacture Directions } \\
\hline $\begin{array}{l}\text { Coconut Oil } \\
\text { Swish }\end{array}$ & $\begin{array}{l}\text { Lauren Naturals, } \\
\text { Gwinnett, GA } \\
30024, \text { USA }\end{array}$ & $\begin{array}{l}\text { Coconut oil, oral antiseptic eucalyptol } \\
0.92 \%, \text { menthol } 0.042 \%, \text { methyl } \\
\text { salicylate } 0.060 \%, \text { thymol } 0.064 \%\end{array}$ & $\begin{array}{l}\text { Place solution in warm water to melt the coconut } \\
\text { oil. Shake well. } \\
\text { Use one tablespoon every morning, noon, and night. } \\
\text { Rinse at full strength and gently swish oil, pulling } \\
\text { it between teeth for 2-3 minutes. } \\
\begin{array}{l}\text { Spit oil out and do not swallow. Rinse mouth } \\
\text { thoroughly with water }\end{array}\end{array}$ \\
\hline $\begin{array}{l}\text { Crest 3D } \\
\text { White }\end{array}$ & $\begin{array}{l}\text { Procter \& } \\
\text { Gamble, } \\
\text { Cincinati, OH } \\
\text { 45202, USA }\end{array}$ & $\begin{array}{l}\text { Water, 1.5\% hydrogen peroxide, glycerin, } \\
\text { propylene glycol, sodium hexametaphos- } \\
\text { phate, poloxamer 407, sodium citrate, } \\
\text { flavor, sodium saccharin, citric acid }\end{array}$ & $\begin{array}{l}\text { Rinse for 1 minute with 15 ml (1/2 fluid ounce or 3 } \\
\text { teaspoonfuls) morning and night. Do not swallow. }\end{array}$ \\
\hline
\end{tabular}




\section{Tooth shade determination:}

Intraoral spectrophotometer VITA Easyshade ${ }^{\circledR}$ Advance (VITA Zahnfabrik, Bad Sackingen, Germany) was utilized to measure the base shade of each tooth before, after one week and after two weeks of conducting the two whitening agents. The participants were seated on the dental chair and reset their heads on the dental chair headrest; instructed to open their mouth a little to expose the anterior maxillary teeth and to keep the tongue relaxed. The six maxillary anterior teeth were measured from right upper canine to left upper canine under daylight of the dental clinic. VITA Easyshade ${ }^{\circledR}$ device was used following the manufacturer's instructions, the tip of the device was placed perpendicular to enamel surface in the middle third of each tooth and the mean values of lightness $\left(\mathrm{L}^{*}\right)$, chroma $\left(\mathrm{C}^{*}\right)$ and hue $\left(\mathrm{H}^{*}\right)$ were registered. Then, the color difference between initial value and week one $(\Delta \mathrm{E} 1)$ and initial value and week two $(\Delta \mathrm{E} 2)$ was calculated with an equation which is: $\Delta \mathrm{E}$ CIE-LCH $=\left[\left(\Delta \mathrm{L}^{*}\right)^{2}+\right.$ $\left.\left(\Delta \mathrm{C}^{*}\right)^{2}+\left(\Delta \mathrm{H}^{*}\right)^{2}\right]^{1 / 2}$.

\section{Pain assessment:}

Pain assessment form that used to assess tooth sensitivity and soft tissue irritation was given to each participant; they were asked to fill in the form daily after using their assigned whitening agent. The pain assessment form showed a scale (WongBaker FACES Pain Rating Scale) that described the intensity of pain or sensitivity during the treatment among six rates: no pain (0), hurts a little bit (2), hurts a little more (4), hurts even more (6), hurts a whole lot (8), hurts worst (10).

\section{Statistical analysis:}

Lightness ad $\Delta \mathrm{E}$ values were statistically analyzed. Tests of normality (Kolmogorov-Smirnov and Shapiro-Wilk) were used; Lightness $\left(\mathrm{L}^{*}\right)$ data revealed normal (parametric) distribution while color change $(\Delta \mathrm{E})$ data indicated non-normal (nonparametric) distribution. Data were displayed as mean, standard deviation (SD), median, and range values. In comparisons between whitening types and between measurement time; for parametric data, repeated measures ANOVA test was used. When ANOVA test is significant, Bonferroni's post-hoc test was used for pair-wise comparisons. To compare the mean age values in the two groups, Student's t-test was used. Mann-Whitney U test was used to compare the non-parametric data of the two groups; while, Wilcoxon signed-rank test was used to test the changes by time within each group. The significance level was determined at $\mathrm{P} \leq$ 0.05 . Statistical analysis was done with IBM SPSS Statistics for Windows, Version 23.0. Armonk, NY: IBM Corp.

\section{RESULTS}

The present study was conducted on 60 subjects and all the females within the two groups showed insignificant difference between mean age values (Table 2).

Table (2): Mean, standard deviation (SD) and results of Student's t-test for comparison between age data of the two groups

\begin{tabular}{|c|c|c|c|}
\hline & $\begin{array}{c}\text { Coconut Oil } \\
\text { Swich } \\
(\mathbf{n}=\mathbf{3 0})\end{array}$ & $\begin{array}{c}\text { Crest 3D } \\
\text { White } \\
(\mathbf{n}=30)\end{array}$ & $\boldsymbol{P}$-value \\
\hline $\begin{array}{c}\text { Age (Years) } \\
\text { Mean (SD) }\end{array}$ & $23.6(3.2)$ & $23.2(3.5)$ & 0.749 \\
\hline
\end{tabular}

*: Significant at $P \leq 0.05$

\section{Lightness ( $\mathrm{L}^{*}$ Value) analysis:}

The repeated measures ANOVA results showed that only the time of evaluation regardless of whitening agent type had a statistically significant effect on mean $\left(\mathrm{L}^{*}\right)$ and as the interaction between the variables is not statistically significant, so the variables are independent upon each other (Table 3).

The interaction results regarding the comparison between whitening agent types: showed that at the base line, after 1 week and 2 weeks there was statistically insignificant difference between mean $\left(\mathrm{L}^{*}\right)$ values in the two groups. While regarding the comparison between the time of evaluation: 
in the Crest 3D White (control group); pair-wise comparisons showed that there was a statistically significant increase in $\left(\mathrm{L}^{*}\right)$ values by time from base line to 1 week as well to 2 weeks. However, for Coconut Oil Swich (study grop); pair-wise comparisons revealed that there was statistically insignificant change in mean $\left(\mathrm{L}^{*}\right)$ values from base line to 1 week followed by a statistically significant increase in mean $\left(\mathrm{L}^{*}\right)$ values from 1 week to 2 weeks (Table 4 \& Figure 1).

Table (3): Repeated measures ANOVA results for the effect of different variables on mean $\left(L^{*}\right)$ value

\begin{tabular}{|c|c|c|c|c|c|c|}
\hline Source of variation & $\begin{array}{c}\text { Type III Sum } \\
\text { of Squares }\end{array}$ & df & $\begin{array}{c}\text { Mean } \\
\text { Square }\end{array}$ & F-value & P-value & $\begin{array}{c}\text { Effect size } \\
\text { (Partial eta squared) }\end{array}$ \\
\hline Whitening agent type & 24.193 & 1 & 24.193 & 1.069 & 0.303 & 0.006 \\
\hline Time of evaluation & 236.221 & 2 & 118.111 & 29.814 & $<0.001 *$ & 0.143 \\
\hline $\begin{array}{c}\text { Whitening agent type x Time of } \\
\text { evaluation interaction }\end{array}$ & 5.806 & 2 & 2.903 & 0.733 & 0.481 & 0.004 \\
\hline
\end{tabular}

$d f:$ degrees of freedom $=(n-1), *$ : Significant at $P \leq 0.05$

Table (4): The mean, standard deviation (SD) values and results of repeated measures ANOVA test for comparison between $\left(L^{*}\right)$ values with different interactions of variables

\begin{tabular}{|c|c|c|c|c|c|c|}
\hline \multirow{2}{*}{ Time of evaluation } & \multicolumn{2}{|c|}{ Coconut Oil Swich } & \multicolumn{2}{|c|}{ Crest 3D White } & \multirow{2}{*}{$\begin{array}{l}P \text {-value (Effect of } \\
\text { whitening type) }\end{array}$} & \multirow{2}{*}{$\begin{array}{c}\text { Effect size } \\
\text { (Partial Eta } \\
\text { Squared) }\end{array}$} \\
\hline & Mean & SD & Mean & SD & & \\
\hline Base line & $57.97^{\text {в }}$ & 3.13 & $58.11^{\mathrm{C}}$ & 3.42 & 0.770 & 0.0001 \\
\hline 1 week & $58.52^{\text {в }}$ & 3.15 & $59.16^{\text {в }}$ & 3.64 & 0.209 & 0.009 \\
\hline 2 weeks & $59.42^{\mathrm{A}}$ & 2.72 & $59.91^{\mathrm{A}}$ & 3.01 & 0.255 & 0.007 \\
\hline$P$-value (Effect of time) & \multicolumn{2}{|c|}{$<0.001 *$} & \multicolumn{2}{|c|}{$<0.001 *$} & & \\
\hline Effect size (Partial Eta Squared) & \multicolumn{2}{|c|}{0.111} & \multicolumn{2}{|c|}{0.156} & & \\
\hline
\end{tabular}

*: Significant at $P \leq 0.05$, Different superscripts in the same column are statistically significantly different

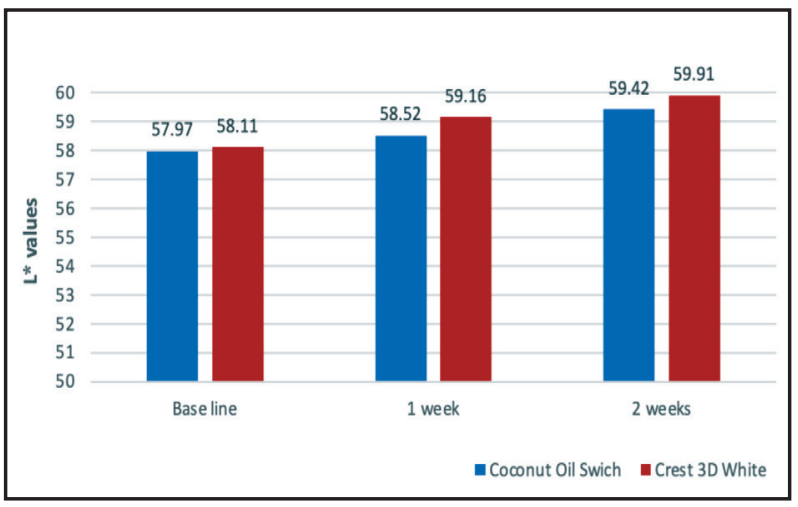

Figure (1): Bar chart representing mean values for lightness $\left(\mathrm{L}^{*}\right)$ with different interactions of variables

\section{Color Difference $(\Delta \mathrm{E})$ analysis:}

Regarding comparison between the whitening agent types: at week $1(\Delta \mathrm{E} 1)$ as well as 2 weeks $(\Delta \mathrm{E} 2)$; Crest 3D White (control group) showed statistically significantly higher mean $\Delta \mathrm{E}$ than Coconut Oil Swich (study group). Considering comparison between the time of evaluation: in Crest 3D White (control group); there was no statistically difference between $\Delta \mathrm{E} 1$ and $\Delta \mathrm{E} 2$; while in Coconut Oil Swich (study group); there was a statistically significant increase in $\Delta \mathrm{E} 2$ (Table 5 \& Figure 2). 
Table (5): Descriptive statistics and results of Mann-Whitney $U$ test for comparison between $\Delta E$ of the two whitening agent types and Wilcoxon signed-rank test for comparison between $\Delta E$ at the two times of evaluation

\begin{tabular}{|c|c|c|c|c|}
\hline $\begin{array}{c}\text { Time of } \\
\text { evaluation }\end{array}$ & $\begin{array}{c}\text { Coconut } \\
\text { Oil } \\
\text { Swich }\end{array}$ & $\begin{array}{c}\text { Crest 3D } \\
\text { White }\end{array}$ & $P$-value & $\begin{array}{l}\text { Effect } \\
\text { size }(d)\end{array}$ \\
\hline \multicolumn{5}{|l|}{1 week $(\Delta E 1)$} \\
\hline $\begin{array}{l}\text { Median } \\
\text { (Range) }\end{array}$ & $\begin{array}{l}0.57 \\
(0-9)\end{array}$ & $\begin{array}{c}3.39 \\
(0-10.69)\end{array}$ & \multirow{2}{*}{$<0.001 *$} & \multirow{2}{*}{0.726} \\
\hline Mean (SD) & $\begin{array}{c}1.24 \\
(1.82)\end{array}$ & $3.79(2.63)$ & & \\
\hline \multicolumn{5}{|l|}{2 weeks $(\Delta \mathrm{E} 2)$} \\
\hline $\begin{array}{l}\text { Median } \\
\text { (Range) }\end{array}$ & $\begin{array}{c}1.7 \\
(0-8.6)\end{array}$ & $\begin{array}{c}3.88 \\
(0-8.61)\end{array}$ & \multirow{2}{*}{$<0.001 *$} & \multirow{2}{*}{1.294} \\
\hline Mean (SD) & $\begin{array}{c}2.32 \\
(2.21)\end{array}$ & $4.08(2.49)$ & & \\
\hline$P$-value & $<0.001 *$ & 0.177 & & \\
\hline Effect size $(d)$ & 1.549 & 0.288 & & \\
\hline
\end{tabular}

*: Significant at $P \leq 0.05$

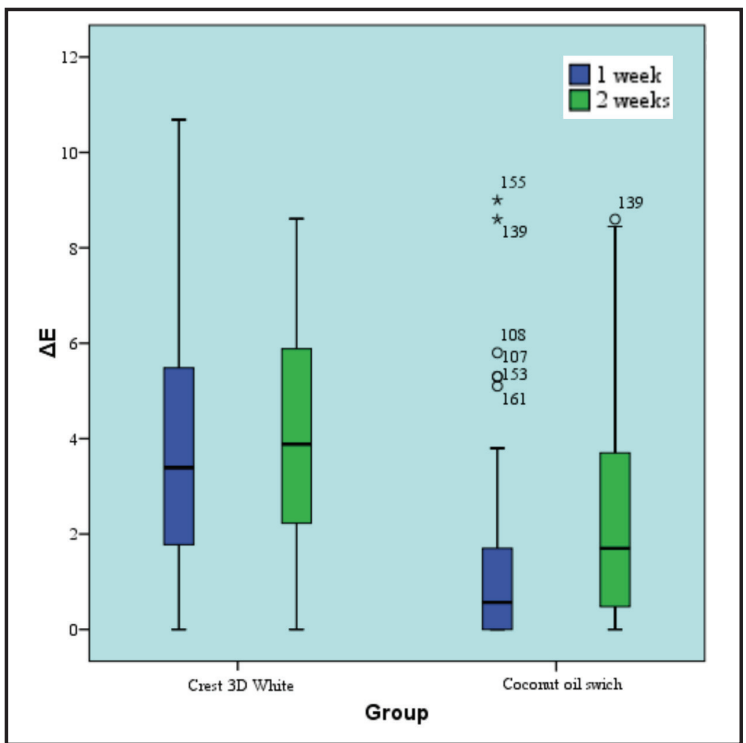

Figure (2): Box plot representing median and range values for $\Delta \mathrm{E}$ with different interactions of variables (Circles and stars represent outliers)

\section{Pain experience analysis:}

Figure 3, shows the percentages of pain experience during the 14-day treatment for the study group (Coconut Oil Swich) and the control group (Crest 3D White) according to (Wong-Baker FACES Pain Rating Scale; 0 - 10). Based on these results, the control group experienced more pain during the treatment (39\%) when compared to the study group (15\%), and more participants reported no pain $(85 \%)$ in the study group compared to the control group $(61 \%)$. The paired t-test results revealed a significant difference in pain scores between the two groups $(\mathrm{p}<0.0001)$ (Table 6).

Table (6): Paired t-test for pain scores during the 14-day treatment according to (Wong-Baker FACES Pain Rating Scale)

\begin{tabular}{|c|c|c|c|c|c|}
\hline Group & Mean (SD) & df & $\mathbf{S}^{2}$ & $\mathbf{t}$ & $\begin{array}{c}\text { Sig. } \\
\text { (2-tailed) }\end{array}$ \\
\hline $\begin{array}{c}\text { Coconut Oil } \\
\text { Swich }\end{array}$ & $1.13(0.04)$ & 14 & 0.03 & \multirow{2}{*}{-13.82} & $\mathrm{p}<0.0001$ \\
\hline $\begin{array}{c}\text { Crest 3D } \\
\text { White }\end{array}$ & $2.38(1.3)$ & 14 & 0.09 & & \\
\hline
\end{tabular}

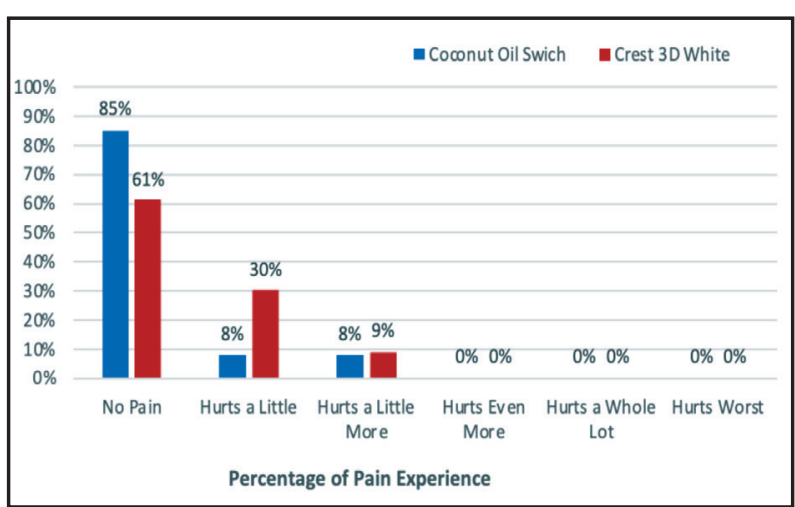

Figure (3): Percentage of pain experience during the 14-days treatment for the Crest 3D White and Coconut Oil Swich groups according to (Wong-Baker FACES Pain Rating Scale) 


\section{DISCUSSION}

This in-vivo study considered one of the very few studies assessing the effectiveness of natural oils as home tooth-whitening agents. Coconut Oil Swish was evaluated in this study which is one of the commercially available coconut oils pulling whitening products in the market. The control whitening agent was Crest 3D White mouth which is one of the over-the-counter bleaching mouthwashes; this mouthwash has been selected because it contains a well-known bleaching agent (hydrogen peroxide) that have great bleaching efficacy ${ }^{(9,17)}$.

Tooth shade measurements have been recorded from all the upper six anterior teeth using VITA Easyshade ${ }^{\circledR}$ device. Digital shade guide was preferred over visual methods for assessment due to its higher reliability and accuracy as suggested by several studies ${ }^{(18-20)}$. Both color difference (delta E) and color lightness $\left(\mathrm{L}^{*}=0\right.$ is black while $\mathrm{L}^{*}=100$ is white) were considered in the statistical analysis; many recent studies support lightness as the critical element of shade matching when investigating a tooth-whitening product ${ }^{(21)}$.

Several studies revealed the efficacy of oil pulling on the reduction of dental plaque, treatment of halitosis and gingivitis ${ }^{(12,22)}$. But up to date, although of the huge online products and numerous websites describe narrative evidence of the use of oil pulling as a natural method to whiten teeth, there is no scientific evidence that proves or disapproves this issue "American Dental Association (ADA) states that insufficient research has been done on oil pulling".

According to the results of this study, Coconut Oil Swish (study group) showed significant increase in lightness $\left(\mathrm{L}^{*}\right)$ and color difference $(\Delta \mathrm{E})$ only after two weeks of use. This result is completely controversy to the results of a single in-vitro study which concluded that there is no evidence that coconut, sesame, or sunflower oils pulling are effective on teeth whitening ${ }^{(23)}$.
In oil pulling, the oil is swished around the oral cavity in morning preferred on empty stomach for about ten to fifteen minutes and concerning must be done to avoid swallowing the oil. The commonly used oils include coconut, sunflower, sesame, corn, palm, soya bean, and rice bran; coconut oil is consisting of $92 \%$ saturated acids and lauric acid represent about $50 \%$ of these saturated acids ${ }^{(24,25)}$. In ancient Indian, it was traditionally believed that the harmful constituents are expelled from the oral cavity when oil is swished ${ }^{(26)}$.

The exact mechanisms of coconut oil pulling therapy are not yet clear; one of the suggested mechanisms of action is that the high viscosity of the oil suppresses the adhesion of bacteria and the accumulation of dental plaque. Moreover, monolauric and monoglycerides of lauric acid that present in the coconut oil proved to have antimicrobial action against some microorganisms. Another possible mechanism is the alkali hydrolysis of fat, which is known as "saponification", or the process of soap formation. The saponification index of coconut oil is high and it contains lauric acid that can react with alkalis exist in the saliva such as sodium hydroxide and bicarbonates producing sodium laureate-soap like substance; these soaps could be effective in dissolving or removing of debris, microbes or plaque materials that enhances cleaning action ${ }^{(12,26-29)}$.

The cleaning action of coconut oil pulling might explain the slight teeth whitening which reported in this study within the Coconut Oil Swish group only after 2 weeks of use. In one week of use, the whitening effectiveness was insignificant which co-accordance with the fact that natural oil pulling therapy needs more time to get an effect ${ }^{(25)}$. It was interesting to find tooth health care brands that used coconut oil in its products; some whitening toothpaste contains coconut oil within its' composition as e.g., "Crest 3D White toothpaste with Coconut Oil"; mentioning foaming and cleaning benefits of the oil. 
The Crest 3D White (control group) results within this study showed that there was an increase in lightness $\left(\mathrm{L}^{*}\right)$ and color difference $(\Delta \mathrm{E})$ after both one and two weeks of use; the increase was significant in lightness $\left(\mathrm{L}^{*}\right)$ and insignificant in color difference $(\Delta \mathrm{E})$.

Although the results in this study revealed no significant difference between lightness of the both group but the color differences $(\Delta \mathrm{E} 1 \& \Delta \mathrm{E} 2)$ in the Crest 3D White (control group) were scientifically higher than in the Coconut Oil Swish (study group). Moreover, $\triangle \mathrm{E} 1$ and $\Delta \mathrm{E} 2$ mean values of Coconut Oil Swish (study group) recorded 1.24 and 2.23 respectively; which are not perceptible clinically as the difference is clinically perceptible only when $\Delta \mathrm{E}$ values are over 3.46 units $^{(30)}$.

This result is consistent with a study of Karadas \& Hatipoglu, $2015^{(9)}$ and Olivia, $2020^{(31)}$, found that whiteness of teeth treated with different hydrogen peroxide and carbamide peroxide containing mouthwashes increased over time and that it was significantly higher than the whiteness of teeth that received no treatment. Moreover, Crest 3D White mouth-rinse recorded the highest recovery whitening efficacy between a group of whitening toothpastes and mouth-rinse products, this study was done on bleached teeth stained in coffee solution ${ }^{(32)}$.

Hydrogen peroxide is an effective whitening agent due to its instability and dissociation, generating oxygen and free radicals; that could interact with the organic pigment complex molecules inside the tooth and divide them into small and less complex molecules. These newly created molecules will reflect more light waves, resulting in a look that is lighter in color; the chromatic particles dislodged or decolored ${ }^{(15,16)}$.

In the other hand this result is contradictory to the findings of a previous study that reported no bleaching effect of different peroxide-containing mouthwashes after a period of twenty-one days ${ }^{(34)}$. Moreover, a study was done to assess the safety and efficacy of a tooth bleaching mouthwash that contained $2 \%$ hydrogen peroxide and whitening strips that contained $10 \%$ hydrogen peroxide; these two bleaching methods were used twice a day for a total of one week. The results of this study showed that both methods were well tolerated but those who used whitening strips experienced a significantly higher effect of tooth whitening than those who used the whitening mouthwash ${ }^{(34)}$.

Regarding the pain assessment, a significant difference in pain scores was found between the two groups as Coconut Oil Swich (study group) recorded lower pain score than Crest 3D White (control group). More participants in the control group (39\%) reported mild to moderate discomfort which included tooth sensitivity, burning sensation in the gingiva, tongue and buccal tissues than the study group (only 15\%). Participants reported that these symptoms occurred during the use of the mouthwash when it was in contact with the teeth and surrounding soft tissues and subsided as soon as spitting out the bleaching agent.

This results could be attributed to the nature of the coconut oil; as it is well established that the main advantages of oil pulling as a traditional therapy in the oral and medical field is due to its natural origin, simplicity, pleasant taste, safe, no allergic reactions, low expense, and promote patient compliance (24,25). Additionally, coconut has antimicrobial, anti-inflammatory characteristics attributed to the existence of lauric acid, and can be used as emollient and moisturizer (27). However, some potential adverse health effect has been reported within using oil pulling such as lipoid pneumonia, diarrhea or upset stomach ${ }^{(26)}$.

Although of the low concentration of hydrogen peroxide in the Crest 3D White mouthwash that used in this study (1.5\%), but it is known to cause more tooth sensitivity and soft tissue irritation ${ }^{(35)}$, which is accordance with some studies that emphasize the occurrence of such adverse effects consequent to using at-home mouth rinses and gels containing different concentrations of hydrogen peroxide ${ }^{(36,37)}$. 
In the other hand, The pain experience results of the control group in this study were conversely to other studies that recorded no or less damaging effects when using agents containing a low concentration of $\mathrm{H}_{2} \mathrm{O}_{2}{ }^{(38,39)}$; one study reported that when using mouthwash that contains $1.5 \% \mathrm{H}_{2} \mathrm{O}_{2}$ for 18 months in patients undergoing orthodontic treatment, soft tissue irritation was not registered ${ }^{(40)}$.

Finally, we must mention that comparing the results of this study to other studies was somehow difficult due to the differences in the study protocol, method and time of application, sample size, and tooth shade determination; besides the deficiency of invaluable references on oil pulling effectiveness in teeth whitening.

\section{CONCLUSION}

With the study limitations, it could be concluded that:

- Although the Coconut oil pulling revealed a whitening efficacy after two weeks of use; the whitening mouthwash that contains $1.5 \%$ hydrogen peroxide recorded higher color change at one- or two-weeks use.

- Coconut oil pulling causes less tooth sensitivity and/or soft tissue irritation during regular use when compared to the whitening mouthwash that contains $1.5 \%$ hydrogen peroxide.

\section{REFERENCES}

1. Watts A, Addy M. Tooth discoloration and staining: a review of the literature. Br Dent J. 2001; 190: 309-16.

2. Manuel ST, Abhishek P, Kundabala M. Etiology of tooth discoloration- a review. Nig Dent J. 2010; 18: 56-63.

3. Prathap S, Rajesh H, Boloor VA, Rao AS. Extrinsic stains and management: a new insight. J Acad Indus Res 2013; 1: 435-42.

4. Greenwall-Cohen J, Greenwall L. The single discoloured tooth: vital and non-vital bleaching techniques. Br Dent J. 2019; 226: 839-49.

5. Carey CM. Tooth whitening: what we now know. J Evid Based Dent Pact. 2014; 14: 70-6.
6. Alqahtani MQ. Tooth-bleaching procedures and their controversial effects: A literature review. Saudi Dent J. 2014; 26: 33-46.

7. Demarco FF, Meireles SS, Masotti AS. Over-the-counter whitening agents: a concise review. Braz Oral Res. 2009; 23: 64-70.

8. Blanchard D, van Wissen K. Home-based chemically induced whitening (bleaching) of teeth in adults: A summary of a systematic review. Public Health Nurs. 2020; 37: 626-7.

9. Karadas M, Hatipoglu O. Efficacy of Mouthwashes Containing Hydrogen Peroxide on Tooth Whitening. Scientific World J. 2015; ID \#961403.

10. Kothari S, Gray AR, Lyons K, Tan XW, Brunton PA. Vital bleaching and oral-health-related quality of life in adults: A systematic review and meta-analysis. J Dent. 2019; 84: 22-9.

11. Fiorillo L, Laino L, De Stefano R, D’Amico C, Bocchieri S, Amoroso G, et al. Dental Whitening Gels: Strengths and Weaknesses of an Increasingly Used Method. Gels. 2019; $5: 35$.

12. Asokan S, Emmadi P, Chamundeswari R. Effect of oil pulling on plaque induced gingivitis: A randomized, controlled, triple-blind study. Indian J Dent Res. 2009; 20: 47-51.

13. Hebbar A, Keluskar V, Shetti A. Oil pulling - Unravelling the path to mystic cure. JIOH. 2010; 2: 11-4.

14. Kwon SR, Cortez E, Wang M, Jagwani M, Oyoyo U, Li Y. Systematic review of in vitro studies evaluating tooth bleaching efficacy. Am J Dent. 2020; 33: 17-24.

15. Zhao K, Zong L, Zhang Q, Att W. Clinical comparison between two bleaching techniques: A 180-day follow-up study. Quintessence Int. 2013; 44: 601-7.

16. Pinto MM, de Godoy CH, Bortoletto CC, Olivan SR, Motta LJ, Altavista OM, et al. Tooth whitening with hydrogen peroxide in adolescents: study protocol for a randomized controlled trial. Trials. 2014; 15: 395.

17. Hasson H, Ismail A, Neiva G. Home-based chemicallyinduced whitening of teeth in adults. Cochrane Database of Systematic Reviews 2006, Issue 4. Art. No.: CD006202.

18. Paul S, Peter A, Pietrobon N, Hämmerle CHF. Visual and Spectrophotometric Shade Analysis of Human Teeth. J Dent Res 2002; 81: 578-82.

19. Knezović D, Zlatarić D, Illeš IŽ, Alajbeg M, Žagar. In Vivo and in Vitro Evaluations of Repeatability and Accuracy of VITA Easyshade ${ }^{\circledR}$ Advance 4.0 Dental Shade-Matching Device. Acta Stomatol Croat. 2015; 49: 112-8. 
20. Borse S, Chaware SH. Tooth shade analysis and selection in prosthodontics: A systematic review and meta-analysis. J Indian Prosthodont Soc. 2020; 20: 131-40

21. Browning W. use of shade guides for color measurement in tooth -bleaching studies. J Esthet Restor Dent. 2003; 15: S13-S20.

22. Amith HV, Ankola AV, Nagesh L. Effect of oil pulling on plaque and gingivitis. J Oral Health Comm Dent. 2007; 1: $12-8$

23. Wheater M, Friedl ZW. Effect of oil pulling on tooth whitening in vitro. J Adv Dent Res. 2016; 7: 20-3

24. Naseem M, Khiyani MF, Nauman H, Zafar MS, Shah $\mathrm{AH}$, Khalil HS. Oil pulling and importance of traditional medicine in oral health maintenance. Int $\mathrm{J}$ Health Sci (Qassim). 2017; 11: 65-70.

25. Saher F, Hosein M, Ahmed J. Role of coconut oil pulling on oral health - an overview. J Pak Dent Assoc. 2018; 27: 94-9.

26. Mythri H. Oil pulling: A traditional method on the edge of evidence. Dent Hypotheses. 2017; 8: 57-60

27. Shanbhag VK. Oil pulling for maintaining oral hygiene - A review. J Tradit Complement Med. 2016; 7: 106-9.

28. Lakshmi T, Rajendran R, Krishnan V. Perspectives of oil pulling therapy in dental practice. Dent Hypotheses. 2013; 4: 131-4.

29. Asokan S, Rathinasamy TK, Inbamani N, Menon T, Kumar SS, Emmadi P, et al. Mechanism of oil-pulling therapy - In vitro study. Indian J Dent Res. 2011; 22: 34-7.

30. Ghinea R, Pérez MM, Herrera LJ, Rivas MJ, Yebra A, Paravina RD. Color difference thresholds in dental ceramics. J Dent. 2010; 38 Suppl 2: e57-e64.

31. Jorge OS, de Arruda CNF , Torrieri RT, Vivanco RG, Pires-de-Souza F de CP. Over-the-counter bleaching agents can help with tooth whitening maintenance. J Esthet Restor Dent. 2020;1-7.

32. Karadas M. Efficacy of whitening oral rinses and dentifrices on color stability of bleached teeth. Acta Biomater Odontol Scand. 2015; 1: 29-34.

33. Potgieterand E, Grobler SR. Whitening efficacy of three over the-counter oral rinses. S Afr dent J 2011; 66: 128-31.

34. Gerlach RW, Tucker HL, Anastasia MK and Barker ML. Clinical trial comparing 2 hydrogen peroxide tooth whitening systems: strips vs pre-rinse. Compend Contin Educ Dent. 2005; 26: 874-8.

35. Tredwin CJ, Naik S, Lewis NJ, Scully C. Hydrogen peroxide tooth-whitening (bleaching) products: review of adverse effects and safety issues. Br Dent J. 2006; 200: 371-6.

36. Brooks JK. Chemical burn to the gingiva after misuse of an over-the-counter oral whitening mouthwash. Gen Dent. 2017; 65: 34-6.

37. Dourado Pinto AV, Carlos NR, Amaral FLBD, França FMG, Turssi CP, Basting RT. At-home, in-office and combined dental bleaching techniques using hydrogen peroxide: Randomized clinical trial evaluation of effectiveness, clinical parameters and enamel mineral content. Am J Dent. 2019; 32: 124-32.

38. Walsh LJ. Safety issues relating to the use of hydrogen peroxide in dentistry. Aust Dent J. 2000; 45: 257-69.

39. Lilaj B, Dauti R, Agis H, Schmid-Schwap M, Franz A, Kanz F, et al. Comparison of bleaching products with up to $6 \%$ and with more than $6 \%$ hydrogen peroxide: whitening efficacy using BI and WI ${ }_{D}$ and side effects - An in vitro Study. Front Physiol. 2019; 10: 919.

40. Boyd RL. Effects on gingivitis of daily rinsing with $1.5 \%$ $\mathrm{H}_{2} \mathrm{O}_{2}$. J Clin Periodontol. 1989; 16: 557-62. 